\title{
SER PAI NO SUBÚRBIO FERROVIÁRIO DE SALVADOR: UM ESTUDO DE CASO COM HOMENS DE CAMADAS POPULARES ${ }^{1}$
}

\author{
Vânia Bustamante*
}

\begin{abstract}
RESUMO. Realizamos um estudo de cunho etnográfico com homens de camadas populares, pais de crianças menores de seis anos, procurando conhecer suas vivências em torno da paternidade e estabelecendo nexos com discursos e práticas. Utilizamos observação participante, através de visitas frequientes aos domicílios, por um período de nove meses, e entrevistas semi-estruturadas. Observamos que, para os informantes, sentir-se pai não está determinado pelo laço biológico com a criança, e sim, fortemente influenciado pela qualidade da relação com a parceira e a própria experiência como filho. Ser provedor é condição necessária para ter uma relação afetiva com os filhos, da qual os cuidados corporais tendem a estar excluídos, por serem considerados atribuição feminina. Estar presente como pai envolve múltiplos sentidos, tanto concretos quanto psíquicos. Sugerimos por fim que o tema continue a ser estudado, diferenciando-se três dimensões - sociocultural, relacional e individual -, e que seja incluído nas reflexões sobre práticas de saúde.
\end{abstract}

Palavras-chave: paternidade, gênero, masculinidade.

\section{BEING A FATHER IN THE RAILROAD SUBURB OF SALVADOR: A STUDY CASE WITH MEN FROM POPULAR CLASSES}

\begin{abstract}
We have developed a study under ethnographic basis with men from popular classes, fathers of children under 6 years old, trying to find out their experiences regarding paternity; making logical links between discourse and practice. We used participative observation, through frequent visits to homes for a nine-month period and semi-structured interviews. We have found that, for the interviewed men, the feeling of being a father is not determined by the biological link to the child, but strongly influenced by the quality of relation they have with their female partner and their own experience as a son. Being a provider is a necessary condition to have an affective relation with their children, in which physical care tends to be excluded as they consider it to be a feminine work. Being present as a father involves multiple, concrete, and psychic senses. As a conclusion, we suggest that this subject should be kept on continue studies, noticing three different levels - socio-cultural, relational and individual - and it should be included in the health practices discussion.
\end{abstract}

Key words: paternity, gender, masculinity.

O conhecimento sobre a participação do homem na vida familiar e na esfera reprodutiva é ainda escasso, dado que tradicionalmente a masculinidade tem sido menos estudada que a feminilidade. No entanto, recentemente esta temática está cobrando espaço no âmbito das ciências sociais, especialmente dentro da perspectiva de gênero. Tal fato está vinculado a desdobramentos das conferências internacionais de Beijin e do Cairo, nas quais se colocou a necessidade de incluir os homens nas políticas de saúde reprodutiva, o que faz necessário incluí-los na pauta de pesquisa (Giffin \& Cavalcanti, 1999; Heilborn \& Carrara, 1998).
A paternidade é um tema estudado tanto no âmbito da psicologia quanto nas ciências sociais e na saúde pública, sendo abordado de forma peculiar por cada disciplina. No presente trabalho estudarei a experiência de homens que exercem a paternidade de crianças pequenas, tomando como base teórica o enfoque socioantropológico, com ênfase na perspectiva de gênero.

Algumas mudanças sociais, tais como o ingresso da mulher no mercado de trabalho e as novas tecnologias reprodutivas, têm impacto na renegociação do significado da paternidade. Nesse contexto surge o conceito do "novo pai", que considera a paternidade como uma oportunidade para expressar sentimentos,

\footnotetext{
Apoio: Programa Interinstitucional de Metodologia de Pesquisa em Gênero, Sexualidade e Saúde Reprodutiva.

* Mestre em Saúde Coletiva. Doutoranda pelo Instituto de Saúde Coletiva, Universidade Federal da Bahia (ISC/UFBA).
} 
participando ativamente no cuidado dos filhos e tendo uma relação igualitária e fluida com a parceira, o que se expressa na divisão de tarefas (Lupton \& Barclay, 1997). No entanto, trata-se apenas de uma das noções dominantes sobre como se espera que os homens se comportem. Por outro lado, espera-se que os homens participem ativamente da esfera econômica, que sejam provedores da família e que construam sua identidade masculina através do papel de trabalhadores (Cáceres, Salazar, Rosasco \& Fernández, 2002).

La Rossa (citado por Lupton \& Barclay, 1997) argumenta que a paternidade contemporânea é um fenômeno de classe média, acrescentando que o conceito do novo pai tende a empobrecer a experiência da paternidade, rica e em constante mudança, ao reduzi-la à forma como os homens se envolvem no cuidado dos filhos. Outra limitação de muitos estudos sobre paternidade seria deixar de lado diferenças socioeconômicas, educacionais, étnicas e culturais.

Ao revisar pesquisas que se focalizam no estudo da experiência da paternidade, encontram-se alguns pontos em comum, tais como a centralidade da dita experiência na vida do homem, a tendência a considerá-la natural e, ao mesmo tempo, marco de uma nova etapa em que se assumem responsabilidades (Arilha, 1998). Por outro lado, vários estudos chamam a atenção para a estreita relação entre a forma como a paternidade é vivenciada e praticada e a relação com a mãe dos filhos (Alatorre \& Luna, 2000; Fuller, 2000; Olavarría, 2000).

Alguns estudos mostram que, para os homens, as mulheres continuam sendo protagonistas naturais no cuidado dos filhos, porém isto é pensado de forma diferente em função do país, da classe social e da idade. Assim, na Inglaterra (Lupton \& Barclay, 1997) e na Grécia (Maridakki-Kassotaki, 2000) os homens expressam desejos de "aprender" a ser pais mais próximos dos filhos. No contexto latino-americano, especialmente nas camadas populares, os homens tendem a sinalizar os cuidados físicos como próprios da mulher (Alatorre \& Luna, 2000; Cruz, 1998; Olavarría, 2000). Por outro lado, em diferentes países, os pais mais jovens estariam mais dispostos a se envolver nos cuidados corporais dos filhos (Lupton \& Barclay, 1997; Olavarría, 2000; Segalen, 2000).

$\mathrm{O}$ desejo de ter proximidade emocional com os filhos está presente em todas as camadas sociais. Nas camadas populares, conquanto predomine uma visão tradicional dos papéis parentais, o papel de provedor exercido pelo homem é necessário, porém insuficiente, dado que existem outras tarefas consideradas próprias de pai: educar, ajudar nos deveres, brincar etc. (Alatorre \& Luna, 2000). Dessa forma, o pai ideal, além de responsável, deve ser carinhoso, compreensivo e saber ter proximidade com o filho (Infesta, 1998).

Para a construção da presente proposta de pesquisa, retomo sugestões deixadas por outros autores no sentido de iniciar uma escuta dirigida aos homens das famílias (Bastos, Ramos de Alcântara \& Ferreira-Santos, 2002), procurando aproximar-me de sentimentos, vivências e percepções masculinas em relação com os papéis sexuais (Bilac, 1995).

Coloco como objetivo estudar a experiência da paternidade em homens que são pais de crianças menores de seis anos, que pertencem às camadas populares e que são usuários do Programa de Saúde da Família. Busco compreender a relação entre o que os informantes vivenciam, o que eles verbalizam - o discurso -, e o que fazem no seu cotidiano - as práticas. Penso que se trata de uma população que precisa ser mais estudada e compreendida, a fim de pensar em formas de atender melhor às suas necessidades e incluí-los em práticas de saúde. Escolhi estudar pais de crianças pequenas, menores de seis anos, por considerar que as diferenças de gênero tendem a estar mais naturalizadas quando se trata de cuidados que acontecem nos primeiros anos de vida da criança (Parseval, 1986) e que fazem falta estudos que problematizem dita tendência.

Concordo com a perspectiva de Lyra e Medrado (2000), para quem a falta de informação acerca dos pais nas pesquisas demográficas no Brasil é ao mesmo tempo expressiva e construtora da realidade. Um mecanismo semelhante estaria em ação na dificuldade de incluir os pais em atendimentos como o pré-natal por parte de profissionais de saúde (Siqueira, Mendes, Finkler, Guedes \& Gonçalves, 2002). Desta forma, ao estudar vivências masculinas e dar-lhes visibilidade, espero contribuir para a construção de eqüidade de gênero, particularmente no marco das práticas de saúde.

\section{MÉTODO}

O presente trabalho constitui um recorte de uma pesquisa mais ampla, que teve como objetivo estudar a participação paterna no cuidado da saúde de crianças menores de seis anos no contexto familiar.

Trata-se de estudo exploratório, de cunho etnográfico, na medida em que procurei me aproximar de um tema pouco estudado através da observação de interações cotidianas no seu ambiente natural. Em tal sentido, a observação participante foi um meio privilegiado para ter acesso aos informantes, através de visitas freqüentes, que se deram duas vezes por semana durante um período de nove meses, e que foram 
registradas em diário de campo. As visitas eram marcadas com antecedência, podendo acontecer tanto de manhã quanto à tarde, em dias de semana e ocasionalmente aos sábados, tendo uma duração média de uma hora. Esta técnica permitiu observar as situações com que os informantes se deparam normalmente, e como estes se comportam diante delas, para posteriormente descobrir as interpretações que eles têm sobre os acontecimentos observados (Becker, 1994). Em forma complementar, realizei entrevistas semi-estruturadas com sete informantes homens e nove mulheres.

O trabalho de campo aconteceu em "Prainha", nome fictício de um bairro do subúrbio ferroviário de Salvador, entre agosto de 2003 e abril de 2004. Iniciei o contato com o apoio de profissionais da Unidade de Saúde da Família do bairro. Num segundo momento, que durou dois meses, optei por continuar as visitas em companhia de uma jovem assistente do bairro. A partir do terceiro mês concentrei-me em seis famílias com crianças pequenas, que considerei típicas, tendo como referência o contato prévio com moradores de aproximadamente cem residências.

A escolha das famílias também esteve orientada por considerações de ordem prática - especialmente a afinidade com os informantes e a acessibilidade da moradia - e teórica, particularmente a diferenciação entre família nuclear, família novo arranjo, família extensa e família monoparental, utilizada em estudos anteriores (Bastos, 2001). Por estar realizando a primeira abordagem de uma temática pouco estudada, optei por excluir famílias em que não havia a presença física do pai, nem contato com este, já que nelas seria mais difícil observar o fenômeno de interesse. Considero que esta é uma tarefa a ser retomada em futuras pesquisas.

No presente trabalho concentrei-me em sete informantes, pais de crianças pequenas, a quem me refiro usando nomes fictícios. Adicionalmente incluí alguns comentários feitos por Jonas, um jovem de 20 anos, com quem conversei apenas uma vez, mas cujo depoimento foi importante para o estudo.

$\mathrm{O}$ vínculo com os informantes se deu através da relação com a família, o que na prática implicava um contato mais frequiente com as mulheres. O contato, pleno de significados e afetos, atravessou diferentes momentos. No início percebia expectativas de obter algum benefício material em consequiência das minhas visitas. Tal atitude, embora não desaparecesse por completo, foi deixando espaço ao gosto de ser visitado, assim como à valorização da conversa e à possibilidade de compartilhar parte da própria vida comigo.

No início do trabalho de campo, a relação com cinco dos sete informantes foi menos fluida do que com as mulheres, talvez porque para os homens do bairro é raro, ainda mais do que para elas, conversar com uma mulher com minhas características: branca, estrangeira e de classe média.

Desde o início expliquei aos informantes o tema geral da pesquisa, inclusive através da leitura do Termo de Consentimento Livre e Esclarecido, que foi apresentado aos participantes após a aprovação do projeto pelo Comitê de Ética em Pesquisa do Instituto de Saúde Coletiva da UFBA, e assinado por eles. Os cuidados éticos vinculados com o sigilo se deram em três níveis igualmente importantes: preservar a identidade dos informantes no nível de divulgação da pesquisa, manter o sigilo dentro do bairro e no interior de cada família.

Seguindo a proposta de Becker (1994), por realizar uma pesquisa baseada na observação participante, partes importantes da análise foram realizadas ainda durante a coleta de dados, de forma a orientar momentos posteriores da mesma, especialmente o roteiro da entrevista realizada na etapa final do trabalho de campo. A diferenciação entre discursos, vivências e práticas foi importante tanto para orientar o trabalho de campo quanto para organizar a análise.

Os resultados, apresentados a seguir, foram organizados em cinco temas: a) A paternidade e o cotidiano do bairro; b) A chegada da paternidade e seu lugar na identidade dos informantes; c) Aprendendo a ser pai a partir da experiência como filho; d) As diferenças de gênero e a estruturação dos cuidados corporais; e) A pluralidade de sentidos em torno da presença paterna.

\section{A PATERNIDADE E O COTIDIANO DE PRAINHA}

Prainha é um bairro localizado na entrada do subúrbio ferroviário de Salvador. $\mathrm{Na}$ área em que moram os informantes, as casas foram entregues a antigos moradores de palafitas há mais de vinte anos, sendo construções de madeirite, progressivamente transformadas em casas de alvenaria. A maioria continua em construção, especialmente pelos filhos, que habitualmente constroem a própria casa sobre a laje da casa dos pais - freqüentemente apenas da mãe.

Os moradores, que se consideram pobres, têm acesso a serviços básicos em forma ainda precária, com instalações muitas vezes clandestinas e freqüente falta d'água. É comum que reclamem da insuficiência dos serviços de saúde, assim como do baixo número de escolas e creches. A limitada inserção no mercado de trabalho - a maioria faz bicos - contribui para restringir o acesso ao transporte público e às opções de lazer que ficam na cidade. $\mathrm{O}$ bairro alberga igrejas 
católicas e pentecostais, assim como terreiros de candomblé, que funcionam também como espaços de socialização para adultos e crianças.

Embora considerem que o bairro não oferece suficientes alternativas de lazer, os informantes, como muitos homens do bairro, participam de reuniões espontâneas em torno de tabuleiros onde jogam dominó e outros jogos de mesa. O baba, jogo de futebol improvisado, é outra das atividades de lazer dos homens. Menos frequientes são as rodas de capoeira, que acontecem alguns finais de semana.

A violência em suas várias formas, inclusive a doméstica, é fonte de preocupação entre os moradores. Com certa freqüência aparecem relatos sobre abusos, inclusive assassinatos, cometidos pelos policiais do posto do bairro contra moradores, especialmente homens, às vezes pais de crianças pequenas. Também é comum que aconteçam brigas, especialmente em bares, que podem ter como conseqüência feridos e mortos.

Os informantes têm baixa escolaridade - apenas um concluiu o ensino médio - e trabalham em atividades consideradas pouco qualificadas, sob um padrão de instabilidade que faz com que passem períodos empregados e outros desempregados, fazendo bicos. Durante a maior parte do trabalho de campo, quatro informantes - Ed, Rodrigo, Pedro e Diogo - estiveram empregados e representaram a principal fonte de renda das famílias, enquanto os outros três - Adilson, Tinho e Cristóvão - faziam bicos para complementar a renda das esposas ou das mães.

A Tabela 1 traz alguns dados sobre os informantes: nome, idade, número de filhos, discriminando gênero e idade das crianças e explicitando quando não existe ligação biológica com a criança.

Tabela 1. Estrutura familiar e número de filhos dos informantes

\begin{tabular}{|c|c|c|c|}
\hline Informante & Idade & $\begin{array}{l}\text { Estrutura } \\
\text { familiar }\end{array}$ & Filhos \\
\hline Ed & 29 & Nuclear & Sandra (4); Jorge $(1,6)$ \\
\hline Diogo & 35 & Nuclear & Thiago (7); Clever (4) \\
\hline Cristóvão & 35 & Extensa & Anita (3) \\
\hline Rodrigo & 24 & Extensa & Emerson (3) \\
\hline Pedro & 33 & Extensa & $\begin{array}{l}\text { Alex (5) filho da parceira } \\
\text { Matheus (recém-nascido) }\end{array}$ \\
\hline Adilson & 20 & $\begin{array}{l}\text { Extensa e novo } \\
\text { arranjo }\end{array}$ & $\begin{array}{l}\text { Rique (4) filho de criação } \\
\text { Anderson (3) filho de criação }\end{array}$ \\
\hline Tinho & 39 & $\begin{array}{l}\text { Extensa e novo } \\
\text { arranjo }\end{array}$ & $\begin{array}{l}\text { Bruna (4) filha biológica, a única } \\
\text { com quem convive Mariana (6), } \\
\text { Clarisse (7) e Iara (11) filhas da } \\
\text { parceira Cinco filhos de diferentes } \\
\text { idades com quem não convive. }\end{array}$ \\
\hline Jonas & 19 & Extensa & $\begin{array}{l}\text { Um menino ( } 2 \text { anos) e outro a } \\
\text { caminho, não convive com eles. }\end{array}$ \\
\hline
\end{tabular}

Alguns informantes verbalizam que não é preciso ser "genitor" para se sentir pai de uma criança, tal como vemos no seguinte extrato do diário de campo:

"Jonas, de 20 anos, conta que apareceu uma menina grávida que diz que o filho é dele, mas ele não sabe, pois ela andou com vários. No entanto explica: 'já fui perguntar se apareceu alguém dizendo que é pai da criança, mas ninguém apareceu, então eu acho que vou ser o pai dessa criança, não importa que eu não seja o pai"'.

Contudo, existem reservas quando o pai biológico está vivo, ainda que esteja pouco presente na vida das crianças, reservas que se quebram mais facilmente quando este é falecido, inclusive porque se considera que toda criança precisa de um pai:

"Pedro explica que, como o pai de Alex faleceu, agora ele o chama de "meu pai", o que antes não deixava, porque o pai era vivo. Acrescenta que não quer ocupar o lugar do pai de Alex, deixa que a família dele o visite, mas já que ele está assumindo tudo do menino, inclusive as despesas, quer registrálo com seu nome, para poder cuidar bem dele. Quer conversar isso com calma com a família do pai do menino (Extrato de diário de campo)."

Coincidindo com achados de outros estudos (Fuller, 2000), na relação dos informantes com seus filhos biológicos, há coincidência entre o fato de não morar com a mãe da criança, nem ter relação amorosa com ela, e o menor envolvimento com o filho, em comparação com pais que moram com a mãe. O relato de Tinho é expressivo deste ponto:

"Durante uma conversa Tinho se lembra de uma filha dele, explica que é uma menina de seis anos que mora com a mãe na Ribeira: 'não tenho visto ela, sumi e não voltei a aparecer, vou aparecer...' (Extrato do diário de campo)".

\section{A CHEGADA DA PATERNIDADE: EXPECTATIVAS, LIMITES E RESPONSABILIDADES}

Os filhos são parte de um projeto de vida - " $a$ gente cria para o futuro" (Cristóvão), implicam grande investimento (Lupton \& Barclay, 1997), cujo resultado se espera ver a partir da adolescência. Eles envolvem expectativas de retribuições na velhice 
(Olavarría, 2000), de perpetuar a família e os valores inerentes a esta. Assim o expressa Diogo:

\begin{abstract}
"Ser pai significa muita coisa: ficar com eles, conversar, ajudar no dever, ensiná-los, ensiná-los a ser bons filhos, a mais adiante eles perceberem o que a gente fez por eles, e que eles façam o mesmo".
\end{abstract}

A expectativa de que os filhos realizem o que os pais não conseguiram, também referida por Olavarría (2000), é colocada por Cristóvão:

"Quero que ela [Anita, de 3 anos] vá [à escola] cedo, porque ela é inteligente, ela pode aprender muito, aprende mais se começar cedo, e se forma mais rápido, quem sabe ela não faz uma faculdade e ela não vira uma doutora igual a você... por que não?. A gente tem que pensar alto."

Ser pai é uma experiência intensa para os informantes, vivenciada como inerente ao fato de ser adulto e formar uma família. Pode ser sentida como constituinte da identidade, tal como acontece com Diogo, que ao assinar uma rifa, organizada por uma vizinha, escreve os nomes dos filhos, "pai de Clever e Thiago", em lugar de colocar seu próprio nome.

Por outro lado, tal como referido por Arilha (1998), ter filhos é algo que os homens desejam e vinculam com o início de uma nova etapa na vida: acaba a curtição e começa a vida familiar e a responsabilidade. $\mathrm{O}$ caso de Pedro é ilustrativo:

"Pedro conta que, após se separar pela segunda vez, começou a namorar Cristiane, pois acha que não é bom ficar sem mulher. Então sentiu que Alex, o filho dela, o prendeu a ela: "Alex me fez apagar meu desejo de ter um filho". Explicou que nessa época ele tinha muita vontade de ser pai, talvez por causa da idade, então poderia ter tido filho com qualquer mulher que não prestasse. Ao conhecer Alex não pensou mais em ter filho. Agora não consegue fazer diferença entre Alex e Tadeu, o filho que teve com Cristiane, sente que ambos são filhos do mesmo jeito (Extrato do diário de campo)."

Em seis informantes a paternidade teve um início não planejado, a partir de uma gravidez inesperada. Assumir o filho implicou mudanças importantes na vida, especialmente a responsabilidade econômica e, no curto prazo, a formação de um novo núcleo familiar. Isto é relatado por Rodrigo:
"Logo quando ela teve o menino, mesmo, quando teve Emerson, ela não tava aqui não. Tava na casa da mãe dela. Mas eu sempre tava lá, entendeu? Sempre tava lá. Na época, mesmo, eu tava até desempregado, mas o dele... tudo o dele, eu comprei. Foi berço, foi cômoda, tudo dele, sem precisar nada de ninguém, entendeu? Saí do trabalho, mas deixei tudo pago, entendeu?"

Seis dos informantes têm um ou dois filhos, e isto tem a ver com uma escolha compartilhada com a mulher, eles consideram que não têm "condição financeira" para ter mais de dois filhos. Neste sentido, Rodrigo e Cristóvão, que têm apenas um filho, desejam mais um (Cristóvão inclusive já escolheu o nome para o futuro filho homem), mas consideram que não podem tê-lo no momento. Neste ponto encontramos coincidências com achados de pesquisas demográficas (Benfam, 1997) e das ciências sociais (Alatorre \& Luna, 2000; Olavarría, 2000) sobre o número ideal de filhos.

Tinho teve seis filhos, em três uniões. Com 39 anos, ele é o mais velho dos informantes, talvez por isso esteja mais próximo da geração anterior, que não usava métodos de controle de natalidade na mesma proporção que na atualidade. No entanto, ele considera que teve demasiados filhos. Numa ocasião comentou que Bruna, a filha mais nova, dá muito trabalho, por isso ele não quer mais filhos: "nem sei como fui ter essa daí, já com filhos moços”.

A limitação do número de filhos se associa com a forma como os informantes vivenciam o núcleo familiar que formaram e com a aceitação de que não necessariamente terão um menino e uma menina, como é o ideal. Isto é explicado por Diogo:

"Ah, eu queria muito ter menina, na primeira e segunda gravidez, mas não veio, veio menino, mas agora minha família é esta mesma. Ana diz que eu quero ter menina com outra mulher, fala disso na frente dos meninos quando brigamos. Eu digo a ela que não tem nada a ver, já teve mulher querendo ter filho comigo, inclusive mulher com melhor condição, mas eu não quis, minha família é esta."

\section{APRENDENDO A SER PAI A PARTIR DA EXPERIÊNCIA COMO FILHO}

A aceitação dos filhos independentemente do sexo, e eventualmente a preferência por meninas, estaria expressando também diferenças entre os homens, entre aqueles que estão dispostos a criar o 
filho e os que só querem "tirar onda e mostrar o filho homem para os amigos" (Diogo). Ao diferenciar-se deste tipo de pai, Diogo lembra do dele:

"Meu pai, mesmo, me tomou de minha mãe aos 6 anos, nunca me deu nada, mas quando tinha reunião com os amigos me levava, todo orgulhoso mostrava o filho homem".

Para os informantes a experiência com o próprio pai, embora influencie, não é determinante na forma de ser pai. Tal como referido por Olavarría (2000), trata-se de uma referência fundamental para ser igual ou para ser diferente; cada pessoa teria essa possibilidade de escolha, inclusive de "dar a volta por cima", mudando um comportamento considerado inadequado.

Por outro lado, outras pessoas - como mãe, tios e avós - podem ser influências positivas que ajudem nesse processo de diferenciação em relação ao próprio pai, tal como aconteceu com Diogo, que foi criado por uma tia, irmã do pai, e morou junto com os avós: "Meus avós sempre me ensinavam o que era bom, o que era ruim, o que devia fazer, o que não deveria. Tudo isso, e aí, hoje eu passo pros meus filhos".

Experiências familiares de criação de irmãos ou sobrinhos são vivenciadas como primeira experiência de responsabilidade, preparatórias para a paternidade, tal como aconteceu com Pedro:

"Quando perguntei a Pedro como se sentia com o nascimento de Tadeu, ele me explicou que já teve a experiência de criar a irmã mais nova, porque o pai dela, marido da mãe, ficou doente; por isso agora não se sente diferente" (Extrato do diário de campo).

\section{AS DIFERENÇAS DE GÊNERO E A ESTRUTURAÇÃO DOS CUIDADOS CORPORAIS}

Os informantes carecem de uma preferência única a respeito do sexo do filho. $\mathrm{O}$ filho homem pode trazer tranqüilidade em comparação com a preocupação constante que gera uma menina:

"Eu mesmo, torcia pra ser homem, né? Que homem a gente deixa em qualquer lugar e mulhé é uma coisa mais difícil, entendeu? Porque a gente imagina, né, como a gente faz com outras pessoas, com outras mulé, a gente imagina, com uma filha minha, um cara vai namorar com ela, faz isso aqui, eu não vou gostar, entendeu? A gente fica com isso na cabeça, entendeu?" (Rodrigo).
A menina traz ternura e maiores expectativas de retribuição no futuro, pois elas ficam mais perto da família: "menina é mais carinhosa, fica mais do lado dos pais" (Diogo). Contudo, a preferência por menina pode não ter a ver com razões práticas, tal como expressa Cristóvão: "eu gosto mais de filha mulher, não sei por que".

Os homens, independentemente de serem pais de meninas ou não, compartilham com as mulheres a expectativa de que a mulher tenha mais proximidade com a menina, e que o homem tenha maior participação em alguns aspectos da vida do menino, por exemplo, que fale sobre sexualidade quando ele crescer, e que desde cedo o leve à rua para se distrair. Isto tem a ver com a idéia expressa por Ed:

"Os meninos ficam mais soltos, com mais liberdade, e as meninas ficam mais presas; o caso de Jorge [ano e meio], mesmo, ele fica nervoso se fica muito tempo dentro de casa, se ele sair fica calmo. Já com Sandra [5 anos] não tem isso".

O corpo da menina, considerado particularmente delicado e vulnerável, só deve ser tocado pela mãe ou alguma outra mulher:

"O menino... até o menino, numa idade de três anos, toma banho sozinho, né, ele já acha que pode tomar banho sozinho. Já a menina não, menina é mais cuidadosa, né?, Raramente, assim, a mãe deixa o pai dar banho, o tio dar banho na menina, né?" (Diogo).

Em vários informantes encontramos dificuldade para tomar contato com o corpo dos filhos, o que se expressaria em negativas a participar de atividades como higiene e arrumação, especialmente no caso das meninas. Isso é considerado "negócio de mulher", e dito ponto de vista é compartilhado por homens e mulheres, tal como expressa Cristóvão:

"Eu não tenho jeito [com] criança pequena, né? Tem aquele cuidado de água não entrar no ouvido, no nariz, então isso aí já é um instinto maternal, uma coisa de mãe mesmo, uma coisa de mãe. Só por isso, se aprende mais pelo lado da mulher mesmo."

No entanto, os informantes referem vivências intensas vinculadas com o corpo dos filhos, tanto meninos quanto meninas,podendo ser a sensação de ter grande ligação com a criança (Lupton \& Barclay, 1997), tal como verbalizado por Jonas: "Eu gosto muito de ser pai, gosto de fazer carinho, pegar no 
colo, brincar... gosto de sentir que sou o pai, de sentir que essa coisinha é minha, que é minha propriedade".

Adicionalmente, é freqüente que os homens expressem preocupação diante de sinais anormais no corpo das crianças:

\begin{abstract}
"Fico com medo dele ficar com o joelho todo ralado, correndo, aí eu não gosto de ver isso, entendeu? Esse caroço aí já me tira do sério, esse caroço, aí, no pescoço dele. Aí, eu acho negativo isso, entendeu? Não é bom pra saúde dele esse tipo de coisa" (Rodrigo).
\end{abstract}

Isto se relaciona com o que afirmam uma profissional de saúde e algumas mulheres das famílias visitadas sobre a excessiva preocupação de alguns homens diante do que consideram alterações no corpo da criança, as quais não teriam importância, mas que eles tenderiam a exagerar, dada sua inexperiência. Isto me leva a pensar que os informantes estabelecem uma relação diferente das mulheres com a realidade corporal dos filhos, não menos intensa, porém marcada por temores.

Se bem que a dificuldade dos homens para estabelecer contato corporal esteja presente com meninos e meninas, é mais intensa com as meninas, o que coincide com o fato de homens e mulheres considerarem que as meninas precisam de mais cuidados corporais que os meninos.

Alguns informantes associam a dificuldade para se relacionar com os filhos em nível corporal, assim como a sensação de não poder acalmá-los quando se sentem angustiados, com a falta de contato freqüente entre pai e filho, devido às obrigações deste último:

\footnotetext{
"Durante uma visita, Rodrigo ficou com Emerson (3 anos) no colo, explicando que tem pouco contato com ele, pois o menino só fica com a mãe, a qual nesse momento tinha saído, e que por isso o menino estava chorando. Enquanto falava, Rodrigo fazia carinho no filho, dizia palavras tranqüilizadoras - 'a mamãe já vai chegar, fique tranqüilo' - beijando-o com muita ternura, e ao mesmo tempo falando: 'Aí fica mais apegado a ela, entendeu? Que a gente, pai, tá mais no trabalho"' (Extrato do diário de campo).
}

O relato de Rodrigo é importante também porque mostra interessantes contrastes entre discursos e práticas, o que me faz pensar em que alguns homens estariam colocando-se e sendo colocados em um papel com o qual não se sentem confortáveis.

\section{A PLURALIDADE DE SENTIDOS EM TORNO DA PRESENÇA PATERNA}

Em consonância com meus pressupostos e com achados de outras pesquisas (Alatorre \& Luna, 2000; Arilha, 1998; Olavarría, 2000), ao falar sobre como consideram que deve ser um bom pai, os informantes coincidem em colocar que deve ser alguém que assuma o filho, o que implica ser provedor e estar presente em sua vida. $\mathrm{O}$ estar-presente adquire múltiplos sentidos, vinculados ao cotidiano das crianças e à sua formação como pessoas, incluindo também a possibilidade de ser uma presença internalizada.

Embora não seja suficiente, o papel de provedor é o mais importante. Assim, diante da falta de recursos para sustentar os filhos, outras dimensões ficam relegadas, e a tendência é "sumir". É o caso de Tinho, que expressa frustração e tristeza por não poder sustentar cinco dos seus seis filhos e com isso ter perdido contato com eles:

"Eu não vou lá, não vou porque chego e o menino tá precisando de alguma coisa e no momento não posso dar nada para eles. Se eu estivesse trabalhando é lógico que não ia faltar nada para eles e nem os daqui também não, mas no momento estou desempregado, não posso dar uma boa atenção para os meninos; porque eu queria ter uma casa grande com um quarto, só para um domingo pegar eles, ficar com eles... então fico triste, chateado."

Por outro lado, ser provedor também traz dificuldades em ter proximidade afetiva com os filhos, dada a falta de tempo para estar com eles, como acontece com Rodrigo:

"Porque eu tenho que cumprir minha obrigação no trabalho, pa ter o pão dele todo dia, entendeu? É por isso, aí, eu quero fazer coisa, quero mesmo fazer, pro bem dele, pro meu bem, ficar mais, saindo na rua, ficar mais divertido, mas eu não tenho tempo pa fazer isso... Quando tenho tempo, não tenho dinheiro, entendeu?"

Encontro que na experiência dos informantes há desconfortos vinculados a expectativas contraditórias em relação à masculinidade: a expectativa de ser um pai emocionalmente próximo dos filhos, que passa tempo com eles, ao mesmo tempo que é provedor. A fala de Rodrigo também é expressiva da valorização de atividades que trazem muita satisfação aos pais que as praticam, tais como ajudar nos deveres escolares, 
brincar com os filhos e "dar o lazer". Esta última dimensão, embora desejada por todos os informantes, é a mais difícil de realizar no dia-a-dia, já que eles não podem dar o que consideram que seria bom para os filhos, devido também à falta de recursos.

Embora quando se trata de cuidados físicos do dia-a-dia, ou diante de doenças, os homens se coloquem e sejam colocados num lugar secundário "Ah, a participação da mãe é essencial, é 100\% indispensável, sem a mãe a gente não pode... " (Ed) em alguns momentos os informantes deixam entrever insatisfação com esta perspectiva.

O acompanhamento realizado com Diogo ilustra esses aspectos. Trata-se de um homem que gosta muito dos filhos, preocupa-se com seu bem-estar e participa ativamente de seu cuidado cotidiano. Nos primeiros meses de visita, Diogo se encontrava desempregado e reclamava dos maus-tratos da esposa: "Ela me maltrata, desconfia de como cuido os meninos; apesar deles estarem bem, ela acha que eu deixo eles na rua e que eles podem se machucar, mas eu estou sempre cuidando". A entrevista aconteceu quando Diogo estava empregado em horário noturno e continuava passando o dia com os filhos, enquanto a esposa trabalhava. Nesta ocasião ele expressou:

\footnotetext{
"A mãe taria em primeiro lugar. O pai toma conta porque não tem jeito, assim, a mãe trabalhando, o pai tem que tomar a frente, né? Mas, melhor do que a mãe, eu acho que não tem".
}

Considero que a mudança no discurso de Diogo teve a ver com o fato de ele ter conseguido emprego, com o qual ele teria voltado a assumir o papel de provedor e a colocar o cuidado dos filhos como um aspecto secundário de sua identidade. Isto também ilustra que as identidades masculinas, das quais a paternidade e a capacidade de ser provedor fazem parte, não são fixas, mas estão em constante transformação, tal como explicam Ginsburg e Lowenhaupt (1990).

Ser autoridade é considerado uma das principais formas de estar presente, uma vez que o homem teria mais capacidade de exercer autoridade que a mulher. Neste sentido, Ed coloca: "Eles sabem que se chorar ela vai fazer, e eu não, não faço mesmo, eu sou um pouco autoritário com eles, ditador (risos), digo não, não e pronto".

Por outro lado, a presença paterna pode ser interna, ao modo do conceito psicanalítico de objeto interno (Grieve, 1999), tal como notamos na fala de Pedro:

\begin{abstract}
"Da mesma forma, tar sempre presente e, quando tá ausente, tar presente também. E porque a criança tem que ter boas lembranças do pai, então quando eu não tou presente a criança vai lembrar, e não vai fazer porque sabe que eu não vou gostar, então eu vou estar sempre presente..."
\end{abstract}

Para alguns informantes, estar presente implica mostrar a realidade e colocar limites aos filhos. Neste aspecto, encontro um interessante contraponto com a forma em que é pensada a presença materna. Durante as entrevistas perguntei a homens e mulheres, em momentos diferentes, o que consideravam um bom pai e uma boa mãe. As respostas dadas pelo casal Paula e Ed são ilustrativas de como os informantes pensam as diferenças entre homens e mulheres. Paula, a esposa de $\mathrm{Ed}$, respondeu que uma boa mãe é quem "Sabe amar seus filhos e dá preferência a eles por cima de tudo, deixar de calçar, de vestir, de comer o que você quer para dar a eles". A resposta de Ed orientou-se no sentido oposto:

"O bom pai hoje é aquele que faz dentro do possível, não se sacrificando por eles, não escondendo a seu filho a realidade da vida, como a gente não esconde de Sandra (...) que eu, pai, não posso dar, não tenho dinheiro mesmo...".

Possivelmente a valorização desta atitude está associada a uma maior distância do homem em relação aos filhos, como acontece nos cuidados corporais; distância considerada necessária para a criação dos filhos, a qual se complementaria com a atitude feminina.

\section{CONSIDERAÇÕES FINAIS}

No presente estudo encontrei que a paternidade é uma experiência que se constrói em vários níveis. Os aspectos socioculturais têm a ver com expectativas preexistentes com relação aos homens: ser provedor de recursos, respeito e autoridade; os aspectos relacionais teriam a ver com estilos de relacionamento com a mãe das crianças e com os parentes; por outro lado, a singularidade de cada homem marcaria diferenças na forma de elaborar experiências passadas e na síntese produzida no momento atual.

O gênero é uma categoria que perpassa os três níveis, expressando-se com especial clareza na estruturação dos cuidados corporais, considerados atribuição feminina. A dificuldade dos informantes em tomar contato com a realidade corporal dos filhos teria 
a ver com o que socialmente se espera deles como homens.

No contexto de Prainha, tenho a impressão de que os homens são valorizados principalmente enquanto provedores econômicos e de respeito, tendendo a excluir contatos e cuidados corporais, embora se espere que o pai tenha proximidade emocional com o filho. Tais expectativas seriam construídas tanto na família quanto através de diversos contatos sociais. A forma como as expectativas se constroem nos contatos intersubjetivos é um tema que merece maior atenção em futuras pesquisas, não limitando-se ao estudo do contexto familiar, mas estendendo-se a outras instâncias de reprodução social, especialmente serviços de saúde e instituições educativas.

Ao estudar as experiências masculinas em torno da paternidade, podemos diferenciar entre aspectos centrados nos homens e outros vinculados com os filhos. Em relação às vivências dos homens, é importante refletir sobre o desconforto expresso por alguns informantes. Assim, enquanto Tinho se lamenta por não poder estar perto dos filhos, dado que não pode sustentá-los, Rodrigo evidencia tristeza ao comentar que não pode estar mais próximo do filho porque tem que trabalhar para sustentá-lo. Por sua parte, Diogo se sente maltratado ao não ser considerado capaz de tomar conta de suas crianças enquanto a esposa trabalha. Estas queixas podem ser pensadas em relação com a coexistência de discursos contraditórios em torno da paternidade- de um lado o discurso tradicional, e de outro o discurso do novo pai-, que por sua vez se contradiz com outros discursos que dizem respeito à masculinidade: expectativas de que o homem seja também um profissional bem-sucedido e provedor da família.

Partindo da preocupação com as crianças, encontramos que, para os informantes, as diferenças entre homens e mulheres têm um caráter complementar: a mãe cuida cotidianamente, enquanto o pai sustenta. Ao mesmo tempo, cada um oferece cuidados que, em conjunto, contribuem para uma boa criação: a mãe cuidaria mais da filha mulher, e o pai estaria mais perto do filho homem, especialmente quando este crescer. Por outro lado, a mãe se entregaria totalmente ao cuidado dos filhos, sacrificando-se pelo seu bem-estar, enquanto o pai não faria grandes sacrifícios, procurando com isso mostrar aos filhos a realidade da vida. Tal visão das diferenças entre homens e mulheres como complementares no cuidado dos filhos faz com que essas diferenças tendam a ser manter, apesar dos desconfortos claramente presentes em alguns informantes.
O presente trabalho pode ser relevante também para se refletir sobre possibilidades de intervenção. Em tal sentido, penso que, dando atenção aos aspectos subjetivos da paternidade - inclusive os contraditórios e irracionais -, conjuntamente com as dimensões relacional e sociocultural, estaremos ampliando nossa compreensão e nos encaminhando a pensar em formas de ajudar os homens que os levem a encontrar meios mais satisfatórios de vivenciar e praticar a paternidade. Tal ajuda poderá dar-se em contextos tão variados como a escola, a consulta médica ou a psicoterapia, contribuindo inclusive para pensar políticas públicas.

\section{REFERÊNCIAS}

Alatorre, J. \& Luna, R. (2000). Significados y prácticas de la paternidad en la ciudad de México. Em N. Fuller (Org.), Paternidades en América Latina (pp.241-275). Lima: Fondo Editorial PUCP.

Arilha, M. (1998). Homens: entre a "zoeira" $e$ a "responsabilidade". Em M. Arilha, S. Ridenti \& B. Medrado (Orgs.), Homens e Masculinidades: outras palavras (pp. 5177). São Paulo: ECOS/ Ed 34.

Bastos. A. C.de S. (2001). Modos de partilhar: a criança e o cotidiano da família. Taubaté: Cabral Editora Universitária.

Bastos, A. C. de S; Ramos de Alcântara, M. A. \& FerreiraSantos, J. E. (2002). Novas famílias urbanas. Em E. da R. Lordelo, A. M. A. Carvalho, S. H. Koller (Orgs.), Infância Brasileira e Contextos de Desenvolvimento (pp. 99-136). São Paulo: Casa do psicólogo; Salvador, BA: Editora da Universidade Federal da Bahia.

Becker, H. (1994, $2^{\text {a }}$ ed.). Métodos de pesquisa em Ciências Sociais. São Paulo: HUCITEC.

Benfam (Sociedade Civil Bem-estar Familiar no Brasil)/DHS (Demography and Health Survey). (1997). Brasil Pesquisa Nacional sobre Demografia e Saúde. Rio de Janeiro: Benfam/DHS.

Bilac, E.D. (1995). Família: algumas inquietações. Em M. do C. B. de Carvalho (Org.), A família Contemporânea em Debate (pp. 29- 38). São Paulo: EDUC.

Cáceres, C., Salazar, X., Rosasco, A. M. \& Fernández, P. (2002). Ser hombre en el Perú de hoy. Lima: Redess Jóvenes.

Cruz, E. F. (1998). "Quem leva o nenê e a bolsa?": o masculino na creche. Em M. Arilha, S. Ridenti \& B. Medrado (Orgs.), Homens e Masculinidades: outras palavras (pp. 5177). São Paulo: ECOS/ Ed 34.

Emerson, R. M., Fretz, R \& Shaw, L. (1983). Writing Ethnographic Fieldnotes. Chicago: The University of Chicago Press.

Fuller, N. (2000). Significados y prácticas de paternidades entre varones urbanos del Perú. Em N. Fuller (Org.), Paternidades en América Latina (pp.241-275). Lima: Fondo Editorial PUCP.

Giffin, K. \& Cavalcanti, C. (1999). Homens e reprodução. Revista de Estudos Feministas, 7(1 e 2), 53-71. 
Ginsburg, F \& Lowenhaupt, A. (Orgs.). (1990). Negotiating gender in american culture. Boston: Beacon Press.

Grieve, P. (1999). Acerca de la noción de objeto interno. Revista de la Asociación psicoanalítica de Madrid, 29(1), 129143.

Heilborn, M. L. \& Carrara, S. (1998). Em cena, os homens... Revista de Estudos Feministas, 6(2), 371-374.

Infesta, G. (1998). Varones adolescentes: los significados de la paternidad en la transición hacia los roles adultos. Em E. D. Bilac, M. I. Baltar (Orgs.), Saúde Reprodutiva na América Latina e no Caribe (pp.211-236). São Paulo: Ed. 34.

Lupton, D. \& Barclay, L. (1997). Constructing fatherhood. Discourses and experiences. London: SAGE.

Lyra, J. \& Medrado, B. (2000). Gênero e paternidade nas pesquisas demográficas: o viés científico. Revista de Estudos Feministas, 8(1), 145-158.

Maridakki-Kassotaki, K. (2000). Understanding Fatherhood in Greece: Father's involvement in child care. Psicologia: Teoria e Pesquisa, 16(3), 1-10.
Olavarría, J. (2000). Ser padre en Santiago de Chile. Em N. Fuller (Org.), Paternidades en América Latina (pp.241-275). Lima: Fondo Editorial PUCP.

Parseval, G. (1986). A parte do pai. Porto Alegre: LCP.

Sarti, C. (2003). A família como espelho: um estudo sobre a moral dos pobres. Campinas: Autores Associados.

Segalen, M. (2000). Antropología histórica de la familia. Madrid: Taurus Universitaria.

Siqueira, M. J. T., Mendes, D., Finkler, I., Guedes, T. \& Gonçalves, M. D. S. (2002). Profissionais e usuárias(os) adolescentes de quatro programas públicos de atendimento prénatal da região da grande Florianópolis: onde está o pai? Estudos de Psicologia (Natal), 7(1), 65-72.

Recebido em 05/11/2004 Aceito em 30/07/2005

Endereço para correspondência: Vânia Bustamante, Rua dos Tamoios 116, apto 402. Rio Vermelho. Salvador -BA CEP 41.940040.E-mail: vaniabus@yahoo.com 